\title{
Deletion Practices in the Era of Permanent Digital Memory
}

\author{
Eric Kula
}

There are a lot of blind spots in historical knowledge. There are countless styles and methods for trying to retain important information about the past. Libraries, books, films, recordings, stories, songs, archives, databases, and hard drives all contain kernels of information and data. However, there will always be events, moments, reactions, and countless other aspects of human experience that will not be recorded. Legal scholar Viktor Mayer-Schönberger reassures us that this "failure" of humanity to capture every piece of information is perfectly "natural", as it mirrors the natural patterns of human physiology: "As our nerve cells process the incoming information, from simple stimuli to pattern recognition, a tremendous amount of information is deliberately lost. It is the first layer of unconscious biological forgetting-and one we rarely realize." (2009: 17) While humans, generally speaking, are not biologically and physiologically constructed to have perfect memory, the impulse to exteriorize information as external resources is a timeless practice, most notably through the creation of language and writing. Through digital technology, the practice of capturing information, and converting information into a storable and recallable resource, has changed drastically.

Many political theorists and cultural studies scholars have attempted to re-theorize the social and political significance of memory in light of the permanence of digital data and the permanent recall of the internet. Undoubtedly, individuals and collectives have coped with these developments by adopting new technological and social habits in order to navigate the world of information. New modes of remembering and forgetting have emerged. Much research has already been devoted to the role of memory in the digital age. Likewise, much scholarship has been devoted to exploring the relationships between permanent memory, privacy, individual rights, freedom of expression and autonomy in the digital age. This article, instead, aims to explore a new emerging trend in digital data management: deleting. New products, programs, laws and habits have been developed that aim to permanently delete data as a form of data security. Rather than focusing on enhanced encryption or secured storage of information, these programs have adopted deletion as a viable technological habit in the social navigation of information. Both data collectors and individuals are exploring the option of erasure as a means to control the role information plays in the era of big data. I argue that these new deletion practices, and new interactions with the digital environment, must be understood as processes which influence the formation of individual and collective consciousness, rather than solely an issue of privacy.

In this article, I aim to explore the issue of deleting data (primarily from the user-initiated side, as opposed to the data collector side) and ask what social and technical consequences may come about as the result of conscious decisions to delete. The empirical observations and examples primarily deal with the individual effort to manage information about oneself (personal details, personal history) in the world of shared information and deep archives. But, I'd also like to suggest that my analysis, drawing on Wolfgang Ernst's media archeology and Bernard Stiegler's philosophy of technology, will illuminate possible consequences for the digital architecture of daily life if widespread deletion becomes a favored mode of data management. First, I address the conditions of archives and data storage, focusing on the technical and economic conditions of archivization which make big data not only possible, but a preferred method of social and market analysis by corporate and government entities. Second, I describe deletion as a practice and detail some of the considerations that one must take before choosing to delete or retain. Deletion practices are often marked by technical, legal and social considerations, and I reference several high profile court cases 
involving Snapchat and Google to highlight these considerations. After I introduce these two core sections, I then take a brief moment to discuss the constitutive role played by technical supplements as theorized by Bernard Stiegler. This section is crucial as I detail my methodological approach to deletion practices through a phenomenological, transductive understanding of archives, technics and populations. I conclude with a section that speculates on the consequences of data deletion (or retention) based on Steigler's account of tertiary memory. Here I suggest that missing, incomplete or purposely deleted data will prompt predictable reactions from the data collector side of big data analysis. I also suggest that the process of human-technical co-evolution will be greatly affected by a social embrace of deletion tactics.

\section{| The Conditions of Archivization}

In order to explore the constitutive role that digital data archives play in society, we must begin with the assumption that the "process" of archivization is determined by the technical and organizational conditions of archives. "As noted by both Derrida in Archive Fever, and Foucault in The Archaeology of Knowledge, the archive is always also a question of the processes and technologies of archivization, the dictums governing what enters the archive, how it enters the archive, how the archive is structured, how it is ordered. For Foucault, the archive is better expressed as the logic of archivization." (Cooke 2009) The logic of archivization is simultaneously the set of rules which will ultimately govern what can be stored and what can be discarded. The process of deletion is part of the logic of archivization. Obviously, big data is a collection of digital practices working in conjunction with today's logic of archivization. Therefore, it is necessary to look at two sets of factors that have led to the emergence of big data. First, one must look at the economic and market driven changes to data storage technology, digitization, and access to stored information. Second, one must also attempt to understand the functionality, organization and dynamic nature of information architecture, specifically the mathematics and algorithms that govern data combinations. To explore the first set of circumstances, I turn to Viktor Mayer-Schönberger's 2009 book Delete: The Virtue of Forgetting in the Digital Age. In this project, he explores the evolution of data storage, the emergence of digitization and the evolution of consumer habits. He does so in a way that identifies the associated "costs" of remembering and forgetting and ultimately concludes that the cost of opting for permanent data retention is far too low and the cost of "forgetting" is far too high for any reasonable alternative to "permanent memory" to thrive. To explore the second set of circumstances, I offer my own interpretation of Wolfgang Ernst's "media archeology" approach to the study of media objects. His work is the flag bearer for a new "Berlin" school of media archeology that differs entirely from Anglo-American approaches to media studies. He is less concerned with the content of media representations and the interpretive engagement with media images, and far more concerned about the actual hardware and software that record media. By focusing on the technical artifacts themselves, I argue that Ernst treats the structure of data storage and the algorithms that maintain that structure as active components in the individuation processes of human-technical co-evolution.

In technology sectors, the idea of perfect memory, permanent storage, infinite depth of archives and lightningfast retrieval is the standard towards which manufacturers now strive. Additionally, many note that the information accessible to everyone through the internet is an important civic tool to help educate the masses and provide as much transparency as possible. Generally speaking, there are a lot of easily identified benefits to a digital culture that defaults into memory/storage. It is not difficult to understand why consumers and manufacturers have attempted to overcome the deficiencies of human memory through digital technology. Even Viktor Mayer-Schönberger, a strong advocate of resuscitating forgetting as a social practice, notes that perfect memory has a number of benefits which are practical. For instance, perfect memory allows individuals to note ideas, capture moments for personal recall, create manuals and procedural guides, avoid previous mistakes and present some level of accountability so that errors are recorded rather than hidden. (Mayer-Schönberger 2009: 10) Indeed, there are countless more reasons why individuals, groups, corporations or governments might aim for perfect memory, more information and easier access.

However, perfect memory certainly has its drawbacks. There are plenty of counter arguments against big data and the now dominant role digital archives play in many aspects of social life. There are a number of perfectly reasonable arguments for why the ability to forget, to move on unhindered by the past, would be a positive to not only individuals, but to collectives as well. On a very practical, individual level, Mayer-Schönberger points out that the inability or unwillingness to forget may lead to the condition in which the future has a chilling effect on the 
present, as we are overly cautious or indecisive in choices and behaviors for fear that they will be permanently stored online. (2009: 10) Despite this trepidation, Mayer-Schönberger argues there has always been a social impulse to move beyond the short comings of biological memory and to create social supplements of memory storage. He argues that the creation of language, and then writing, are both evolutionary steps in the battle for perfect memory and that digitization has pushed the social default permanently away from forgetting toward remembering. The evolution of technologies supporting external memory storage, above and beyond the capabilities of biological memory, has further pushed society toward the default condition of total recall.

But, when studying the effects of data storage and retrievable access on social and political issues, one cannot start from the assumption that perfect memory and eternal storage are default social conditions. The social exteriorization of memory has evolved over time, culminating in our current digital age. According to Mayer-Schönberger, the four elements of the "digital age" that have reduced the capacity of forgetting are: digitization, cheap storage, easy retrieval, global reach. (2009) It is necessary to point out that big data is not the default condition of the world's data storage systems. Rather, it is the logical result and logical extension of new technologies that have emerged into the consumer market place. Just as language and writing were not solely generated as a form of memory extension, they are nevertheless technical creations that exteriorize human memory into the external world. For instance, "it's worth noting that the revolution is being propelled by the convergence of three technology domains: staggeringly powerful but cheap information engines (computing at scale), ubiquitous wireless broadband, and smart sensors. This kind of technology-infrastructure convergence is the hallmark of revolutions. Nearly a century ago, for instance, air travel was enabled by the convergent maturation of powerful propulsion engines, modern aluminum metallurgy, and the emerging petroleum industry." (Mills 2013) Just as the petroleum industry did not develop expressly in anticipation of air flight, the technologies of information engines, wireless broadband and smart sensors all have multiple intentional design traits, one of which is big data collection and processing. Following the Social Construction of Technology school of thought, one could argue that these technologies have put in place the necessary computing power to foster a system of big data, but the actual social organization of data collection and analysis has been crafted by social, governmental and corporate interests. (Pinch and Bijker 2003) It is through the social appropriation of such available technologies that these technologies form the digital architecture of daily life, positioned strategically in such a way that humans (in the form of consumers, patrons, customers, spectators, patients or employees) must interact with them if they wish to participate fully in society. Of course, given the role that such data analysis plays in many industries, we must note that a never-ending supply of fresh, new data (new consumer data points) must come into existence to justify the usefulness of big data enterprises. These data collections technologies do not grow, expand or evolve without a constant stream of human-supplied information. Therefore, the data collection points of big data must be unobtrusive and user-friendly.

Mayer-Schönberger's 2009 book did a good job of historically analyzing the material and economic roots of advanced post-industrial information economies which require digital memory. His conclusion is that "The truth is that the economics of storage have made forgetting brutally expensive." (Mayer-Schönberger 2009: 68) For instance, he points out that analog systems of data storage need to conquer geography, by shipping physical objects from one user to the next. But since digital information is standardized, any digital information can be shared on the same digital network (internet) without the costs or time-delay of dealing with analog objects. Similar to how digital markets far outperform analog markets on the costs of "sharing" information, Mayer-Schönberger also points out that production costs also favor digitization. "Unlike the production of most physical goods- think of shoes or a wooden chair- almost the entire cost of information goods is spent on the production of the first piece, while the making of subsequent copies incurs a relatively negligible cost...This pushes collectors of information to have their information treasures accessed by many others." (2009: 82) Not only does the cost of "re-production" favor the ease and practicality of digitization, but he argues that the cost of this process also produces an incentive to share information and to increase connectivity.

Though the production side and distribution networks of digital data storage have far fewer costs than equivalent analog systems, Mayer-Schönberger suggests that individual consumers also approach these technologies with costs and benefits in mind. He noticed an interesting consumer trend that people seem to prefer higher capacity storage devices, even if cheaper lower capacity devices are available. For the most part, the market accommodates this desire for higher storage capacity. He notes that the costs of personal data storage devices have stayed the same over time, but storage space has increased, as opposed to static storage capacity at declining cost. This is MayerSchönberger's argument for markets, manufacturers and individual consumers drifting toward remembering as the "default condition." The costs of remembering continue to decline. Even the time costs of deciding whether to 
save or delete are too high not to default into remembering. The effort to "save" has diminished, but the value of remembering has soared.

To summarize, Mayer-Schönberger argues that these economic and technical factors are the driving force behind the information economy, rather than a consequence. However, I argue that if we are to explore deletion as a tool of social navigation of data archives in the context of big data, we cannot explain things simply in the vocabulary of "costs," "privacy" or "autonomy." I argue it is essential to understand more fully how data archives (inter)act with populations to constitute humanity, in a time when information circulation and information analysis occur with no temporal or geographic constraints. I will explore this constitutive role of memory storage in the next section. But, first, I turn to Wolfgang Ernst's study of archives and digital memory in an effort to better explain the dynamic power of archives and information as social forces. "Data" are not static objects waiting to be retrieved and utilized by social actors. Given how archives operate, I argue that archives and data themselves operate as social actors. Ernst's attention to the hardware, software and programming of archives help illuminate this point.

Picking up from Mayer-Schönberger's analysis of how digital data archives became so prevalent, Wolfgang Ernst argues that "Once digitized, the electronic sound or image is open to real-time access and new search options such as similarity-based image retrieval. The traditional architecture of the archive has been based on classifying records by inventories; this is now being supplemented or even replaced by order in variation and fluctuation, that is, dynamic access. This 'archive' is no longer simply a passive storage space but becomes generative itself in algorithmically ruled processuality." (2012: 29) Ernst is implicitly stating that the modes of access and modes of data retrieval in digital archives have changed so drastically from traditional archives that our entire understanding of "information" needs to be updated. In the digital archive, there is no such thing as static information. It is constantly in flux. Through the algorithmic modes of data management, data is permanently recombined and recontextualized, constantly forming "new" data points, presented in new forms and new temporalities. The archive itself, through the rules that govern its ordering, comes to generate data for the social world. "Algorithmic objects are objects that come into being anew and processually; they do not exist as fixed data blocks." (Ernst 2012: 82)

Indeed, the conditions that make digital archives possible also guarantee that that which is archived will differ from earlier modes of information storage. "The testimonial function of archival records was once firmly rooted in their material authenticity." (Ernst 2012: 88) This is no longer the case, as material authenticity is foreign to the immaterial nature of numeracy and algorithm-based logic of materiality as code. In stark contrast to physical buildings, or library cataloging systems, in which recorded pieces of information were saved and preserved to maintain the fidelity of the information, the primary purpose of the archive is to retrieve information in ways that are combinable, transferrable and accessible by algorithmic calculations. As such, "addresses for such (non-)places of memory are less spatial and more defined by their temporal modulations." (Parikka 2011: 58) This is what Ernst means when he claims that archives operate in contrast to the historically linear progression of time. He argues that the primary characteristic of the digital archive is the vectorial and orthoganol aspects of information recall which only operate in "microtemporality" compatible with the digital processing power of archives, and it factors into the phenomenological experience of the macrotemporality of the social, historical world. "The microtemporality of the data processing operations (synchronization) is thus superimposed on the historical archive's macrotime." (Ernst 2012: 85) And, the very nature of this shift in archives is ontological. "In short, it is the calculation-and number-logicbased ontology of technical (and especially computational) media through which cultural memory gets articulated instead of the literary-based narrativization favoured ontologically and epistemologically by historians through which to think media archeology... The issue of 'digital memory' is then less a matter of representation than of how to think through the algorithmic counting ontology of a memory." (Parikka, 2011, p. 57)

Lastly, I would like to focus on the transition from the algorithmically generated to the algorithmically degenerated. Ernst touches on something critically important to the study of information navigation. If we understand digital archives as partially defined by permanent flux, transfer and reorganization, this helps us understand Ernst's claim that data points do not exist outside of the algorithm. However, if algorithmic objects are objects that come into being anew and processually, then they are tied to the temporal necessity of the algorithm itself. This "dynamic access" of archives is one of appearance and disappearance depending on the selected search methodology. When an algorithmic object is not being generated, it does not exist, a glaring difference to the book that remains dusty on the shelf when not being accessed. Ernst declares that archives demonstrate the "potential complicity of cultural memory media in the symbolic exchange of presence and disappearance. Digital storage media are potentially involved in the erasure of data." (2012: 93) He also declares "Characteristic of digital archives is the fact that they can be instantaneously erased-faster than by any fire in the library at Alexandria." (Ernst 2012: 93) Indeed, I suspect 
Viktor Mayer-Schönberger would agree that a crucial feature of digital data storage, and a reason for its popularity, is the ability to quickly delete, replace, rewrite or copy over the used space of memory. It is somewhat ironic that the "dynamic access" to information and memory is only made possible by the algorithms that govern the archives, and yet the very nature of these calculations is that that they must simultaneously delete, update and reorganization information, constantly nullifying the preceding calculation. It is in this odd dichotomy of constant appearance and disappearance that we can most clearly articulate Ernst's claim that the digital archive and the physical archive operate on distinctly different temporal planes.

\section{Deletion as a Practice}

In a recent book about bureaucracy and the historical role played by paperwork in the management and subjugation of society, Ben Kafka mentions certain moments of political resistance that have been carried out in, through or against paperwork. In one particularly powerful tale, Kafka discusses the exploits of Charles-Hippolyte Labussière, who hid and destroyed documents while working for the Committee of Public Safety Prisoner's Bureau in 1794 to save accused citizens from the guillotine. (2012) I reference this example to highlight two points about the politics of archives. First, it demonstrates that bureaucratic information storage, the precursor of today's massive digital archives run by governments or corporate entities, holds a certain power within institutionalized processes, such as the justice system. The power of memory and of information is intertwined with the social, economic and legal power structures of society. Secondly, this tale highlights how loss, deletion or rendering irretrievable of data can be conceived not only as an error in memory but as an action of political resistance or symbolism. The act of deleting information can be seen as political in a number of ways depending on the context of the deletion. It can be seen as an exercise of power through an autonomous act to control/delete information about oneself. It can also be seen as an exercise of power relative to an external other than has an interest in maintaining and recalculating data. Deleting can also be an example of systemic power networks operating in ways that enhance or solidify the circuitry of power flows, such as forcing people to "refresh" information about oneself.

In some situations, the decision to erase can be complicated and worthy of much conscious attention from an individual user, while at other times a decision or conscious user-initiated action isn't necessary at all and the act of deletion is carried out by data collectors with no input or awareness from the individual tied to the data in question. The point is that deletion of information in today's context, the emerging era of big data, is something that entails issues of power, privacy, autonomy and memory. In addition to the political and social ramifications of opting to delete or save, one must also be aware that the practical possibility of deleting data from archives can involve complicated interactions from technical and legal obstacles. For instance, the recent surge in popularity for such apps as Snapchat (apps that leave "no trace" of communications) could be interpreted as perhaps an increase in awareness of data surveillance, or a social psychological shift towards embracing the temporary and ephemeral over the permanent. However, the promise of "no trace" cannot necessarily be achieved as simply as using an app like Snapchat. There are countless technical and legal issues surrounding how an app "deletes" data, as well as what other data it may record tangentially to the process of deletion. For instance, in 2014, Snapchat settled a dispute with the Federal Trade Commission over how they misrepresented the way that content "disappears." "The FTC found that while Snapchat was marketing their photo app as a truly ephemeral product, they were tracking user data such as location, contacts, and phone numbers, therefore misrepresenting their privacy and security settings." (Mosendz 2014) Using Snapchat can generate new data trails, despite the fact that many users turn to such apps precisely as a way to avoid leaving digital traces.

In another high profile case, the European Union Court of Justice ruled that search engine Google must comply with individual's requests to remove personal information from its search results. The enforcement of the so-called "Right to be Forgotten" gives individual "data subjects" enhanced rights in seeking to limit details about themselves online. Judges from the European Union Court of Justice declared that "If it is found, following a request by the data subject, that the inclusion of those links in the list is, at this point in time, incompatible with the directive, the links and information in the list of results must be erased..." (http://www.nbcnews.com/tech/security/europestop-court-backs-right-be-forgotten-google-case-n104486, May 27, 2014.) Though this appears as a valuable new resource for those who wish to embrace deletion practices as a form of social data navigation, this ruling is fraught with technical and legal complications. For instance, Google needs to develop the appropriate technical pathways 
for people to make such requests, which can be a complicated endeavor. Also, Google needs to establish procedures for exactly how they will determine which requests should be honored and which requests do not meet the legal threshold to qualify as that which can be "forgotten." Moreover, "Because the court's ruling applies only within Europe, it will mean some fragmentation of search results. That is, Europeans and Americans will see slightly different versions of the Internet." (http://www.nbcnews.com/tech/internet/google-right-be-forgotten-rulingunlikely-repeat-u-s-n114731, May 27, 2014) While social attitudes in Europe have pushed to establish this daring new deletion practice, many legal scholars argue that the inherent conflict between the right to be forgotten and the right to freedom of expression may overshadow the intended social outcome of this law. "This could transform Google, for example, into a censor-in-chief for the European Union, rather than a neutral platform. And because this is a role Google won't want to play, it may instead produce blank pages whenever a European user types in the name of someone who has objected to a nasty blog post or status update." (Rosen 2012: 92) In such cases, a wholesale embrace of deletion practices as reinforced by the European Union Court of Justice may lead to censoring other valuable information.

There is no shortage of other examples of the ways in which deletion practices can overlap with technical, legal and social norms. However, there is a shortage of theoretical and philosophical discussion about the ways deletion practices may alter how individuals and groups relate to data collectors and archives in the future if deletion practices become widespread. I suggest approaching deletion as a social practice that people may choose to employ in an effort to navigate big data, to structure the information architecture of their digital lives, and to manage their identity as a construct of data assemblages. In this context, issues of power, privacy, autonomy and memory all come into play, but we can also focus on the everydayness and habitual aspects of deletion as social navigation of information.

People engage in mutually beneficial relationships with data technologies. On the one hand, such voluntary interaction is the simplest way to engage in all the opportunities of modern consumerist society. On the other hand, the price that such convenience entails is that the information history one creates will be used to influence governing techniques and to target individual consumers in the future. Methodologically, this give and take relationship reminds one of the transductive, phenomenological approach to technology studies, detailed in the writings of philosopher Bernard Stiegler. When people are interacting with data storage, or being acted upon by the social application of stored data, the process of individuation is playing out as both human and technical supplements inform and contour each other. This co-evolution, the process of individuation, is critical to understanding how conscious and deliberate interactions with data or the process of data collection is not simply an isolated behavior, or a temporally limited interaction, but rather an exteriorized impulse being discretely recorded and incorporated into the digital architecture of our daily lives.

Therefore, if remembering is now the default condition of society, and if the form remembering is taking is digital data storage due to a confluence of technical products and technological lifestyle habits, then it stands to reason that people will (consciously or subconsciously) amend their daily habits and expectations in such a way that is compatible with perfect memory. They learn to live under default conditions. The latter chapters of Viktor Mayer-Schönberger's book Delete: The Virtue of Forgetting in the Digital Age address several possible approaches a society could take to live with copious amounts of data. He presents a number of possibilities, but then proceeds to poke holes in each argument by pointing out legal, technological, biological or practical reasons why such approaches are not likely to help us come to grips with the default condition of remembering. His possible solutions are digital abstinence, enhanced privacy rights, digital privacy rights infrastructure, cognitive adjustment, information ecology evolution, the social ability to master contextualization of information or deletion of data by setting mutually agreed to expiration dates. (Mayer-Schönberger 2009)

Mayer-Schönberger strongly supports a technological and social solution to the perils of permanent memory by arguing that expiration dates on data will reintroduce forgetting as a valuable social condition. Specifically, he argues that expiration dates should be user-initiated because it will "humanize" the process by mimicking or closely approximating the natural processes of psychological and biological forgetting. Mayer-Schönberger talks about ways that expiration dates could be tweaked so that expiration more closely resembles the decay of human memory. He suggests that as we learn more about memory, neuroscience can invent digital code that can emulate memory decay. He advocates for temporal cues (like reinforcing information that is frequently recalled, or providing visual reminders as information approaches its expiration date) as ways of mimicking real life situations where reminders inhabit our geographic locations. He believes this is the next big step in improving web browsing and consumer experience (Mayer-Schönberger 2009: 193) In addition to his goal of rehumanizing the process and restoring the social significance of forgetting, he also makes some normative prescriptions against permanent memory. He 
believes "The value of information is not timeless" and "good information is preferable to copious information." (Mayer-Schönberger 2009: 173) He also argues that forgetting aids in the process of abstraction and that abstracted knowledge is necessary to expeditiously and decisively operate in our daily lives. He argues that "Using generalizations, relying on conjecture, emphasizing the present, and respecting subsequent experiences, helps us to reason swiftly and economically, to abstract and generalize, and to act in time, rather than to remain caught up in conflicting recollections." (Mayer-Schönberger 2009: 21)

Ironically, Mayer-Schönberger admits that programs facilitating expiration dates cannot be characterized as only subtracting information from existing data sources. Rather, expiration dates are an "addition" to information, actually existing as a new piece of meta-information. When we set a piece of data up to expire, we add a tag of information to the original data point. This observation is crucial to my exploration of the social navigation of information through deletion. Mayer-Schönberger's observation that deleting data simultaneously adds something to the infosphere highlights that data and archives are not simply "dead" or "static" collections of information, but very much alive and fluid (though he may not necessarily agree with this statement, his observations reveal the dynamic nature of the digital archive.) Therefore, accessing information with the intent to delete it is still an action that can be recorded or added to the information infrastructure. Even in deletion you may leave a digital trail. While this process would add to the technical web of information, Mayer-Schönberger believes it should also be user controlled which would eventually humanize the process of data collection by incorporating conscious choice as well as unconscious forgetting. Because the process of user-initiated expiration dates would simultaneously add and subtract our preferential choices to big data webs of information, it would be crucial to "entice" users to explore such options by creating simple user interfaces to which people could acclimate quickly.

Mayer-Schönberger identifies a number of potential difficulties which would likely accompany the widespread implementation of expiration dates on information. While this is his preferred socio-technical solution to overly burdensome archival memory, he is realistic in his tempered enthusiasm and he understands that it will take not only a monumental shift in social behavior but also a number of technological innovations as well as a number of legal compromises from all parties involved. But, beyond his prudent approach to expiration dates, he argues that "clicking delete is not enough." First of all, he claims that once we have "shared" our information, we have lost control of it. In essence, he is arguing that sharing information is a mutual enterprise that entitles both the sender and the recipient to claims over that information, though not necessarily equal claims. Many reliable and transparent legal protections must be in place to guarantee that the sharing of information remains a finite relation. However, he understands that someone wishing to delete information (about themselves or otherwise) will likely require the cooperation of many other parties. For this reason, clicking delete is not enough and this is why Mayer-Schönberger identifies both mutually binding social agreements and technical solutions to the problem. Similarly, Mayer-Schönberger realizes that sharing of information is not a finite operation with a clear start and end. The act of sharing information, or any digital act, creates a trail of "other" information (time and date stamp, related searches, etc...) The original data input may have expired, but a string of other information has automatically been created. In other words, data is de- and re-contextualized at various times in its data lifespan. (Mayer-Schönberger 2009: 86-88) Deleting one piece of information does not guarantee that all information relating to the initial information exchange will be deleted. In fact, the original sender of information may not have any claims over the new information that comes into existence surrounding the original data.

I'd like to flush out "deletion" as a social practice by highlighting a specific example of opting to delete over opting to retain. Just as the Snapchat and Google examples above pointed out that there are countless technical and legal considerations that must be taken into account when choosing to delete, the following example highlights the complex social and contractual obligations of deleting digital data, even when all parties involved are amenable to data deletion as an alternative to securing data. Recently, a secured person to person communications company specializing in encryption and data security between clients introduced a new subscription feature for mobile phone users which allows people to protect their text messages by automatically deleting them after a preset amount of time has passed. This example brings a number of issues to the forefront. In this specific case, there is a clear concern and motivation for privacy. Additionally, the act of deletion requires participation from three separate parties (sender, recipient, communications company) and highlights the interconnectedness of floating data points. This example also highlights the technological and market driven aspects of data management because this particular act of deletion requires a subscription to a specific product.

This secure messaging app allows customers to send private, encrypted messages which the sender can program to auto-delete. The app deletes sent messages and attachments from senders' and receivers' devices. The app works 
very similarly to the idea of expiration dates put forth by Mayer-Schönberger (though he argues that such apps should be implemented in all technical settings that request personal information from the product user.) Using this texting app, the user can set texts, videos, voice recordings or pictures to automatically delete at a pre-specified time after delivery, or recall and destroy any previously sent message at the user's discretion. Additionally, this company's texting application generates a new encryption key for each new message. The key is then destroyed so even if the device is examined, there are no keys to be found.

If we examine this application of "auto-deletion" in the context of Mayer-Schönberger's calls for expiration dates and the "rehumanization" of forgetting, we can see that, though this is but a single example, the prospects of deleting may be on the horizon. But, we should note that the people who sign-up for the services of this secured communications firm are already very concerned about privacy and data protection. The actions taken by these specific subscribers are not necessarily "coping mechanisms" to living in a world of big data, but rather meticulously planned actions. This highlights Mayer-Schönberger's concern that any systems put in place for users to opt for expiration dates must be very user-friendly, or the user will have to be very motivated. The second issue of MayerSchönberger's thesis that this example brings to light is that three distinct parties must be involved if this deletion is going to be successful. The sender of information must be heedful enough to set the auto-delete timer. The recipient must also be consciously involved by being a subscriber to the same secured communications company. This service only works if the recipient is also a willing participant. Otherwise, deleting information that is stored in another person's phone is clearly way out of bounds and an invasion of their privacy. The company is the third party involved, as it supplies the technical mechanisms and must also provide assurances that the messages will not remain on either device, nor show any trace of its transit. This perfectly demonstrates that "clicking delete is not enough" and it must be a mutually agreed upon social action with multiple parties agreeing to deletion. The relevant connection to MayerSchönberger's expiration dates proposal is that this text destroying application will only succeed if there is a receptive marketplace. Mayer-Schönberger has demonstrated that the costs associated with data storage are relatively low and the costs of deletion can be relatively high. In this case, the cost seems very high because this is a subscription service and is only available to paying customers. Obviously, this example only reinforces the ideas of Mayer-Schönberger by setting an actual, premium price on security and the power to delete. It is obviously a technically demanding task that requires much cooperation from clients and companies, and it may seem relatively expensive compared to allowing one's personal data be collected and stored.

This example of deleting texts from two user's devices as well as the data company's internal storage system highlights all the concerns that Mayer-Schönberger identifies about the increasingly comfortable default position of "permanent memory." Deletion is a time intensive and expensive task, relative to default forgetting. This brings me to the final point about this example of auto-deletion, referring back to Mayer-Schönberger's point that deletion simultaneously creates a data trail. On the one hand, in the technical, digital sense, setting something to delete with expiration dates adds a new piece of information to the original data (the expiration date is added.) Other records likely indicate that an erasure or sweep took place at a specific time. Though the content in question may have been deleted, the digital footprint was likely expanded by this action. On the other hand, I would also add that something else has been created, or more specifically, exteriorized. According to philosopher Bernard Stiegler, each individual is constantly living in and through external supplements to daily life. But, instead of drawing firm ontological lines between subject and object, he argues that interiority is nothing more than its exteriorization. By this he means that individuals inscribe themselves into the world around them through their actions, their thoughts and their impulses. Virtually every action or act of creation is an externalization of memory. This "inscription" is actually materialized memory, and the technics and objects around us are externalized memory that constantly bring the past into the present and weigh on how individuals constitute consciousness at every moment. The question is: what exactly is someone exteriorizing into external memory when they seek to delete, hide or erase data?

\section{Individuation and Memory}

"With the exteriorisation of memory comes a loss of memory and of knowledge, which is experienced today in our daily lives,
in all the aspects of our existences, and, more and more often, in the feeling of our powerlessness, if not of our impotence - at
the exact moment when the extraordinary mnesic power of digital networks make us all the more sensible to the immensity
of human memory, which seems to have become infinitely reactivatable and accessible. This seeming paradox means that
the question of hypomnesis is a political question, and the stakes of a combat: a combat for a politics of memory, and more 
precisely, for the constitution of sustainable hypomnesic milieux." (Stiegler http://www.arsindustrialis.org/anamnesisandhypomnesis, February 20, 2010)

Like Wolfgang Ernst, I argue that the internal relations governing data storage and technical capabilities are a dynamic series of shifting calculations and algorithms which affects subtle change in the lives of individuals who are impacted by data surveillance (essentially everyone in post-industrial society.) And, because I am addressing the act of deletion as a conscious choice, or a conscious input and extraction into the algorithmic assemblages of digital life, I believe a phenomenological approach to the problem of memory in the digital age could be helpful. The phenomenology of Bernard Stiegler is my starting point. Stiegler's work on how time is constructed in a socially accessible way starts from the foundational assumption that humans and technology concomitantly co-constitute each other. This is critical to my arguments because I am trying to gauge the importance and impact of a conscious human choice on the technical architecture of daily life.

Stiegler argues that the relationship between the human experience of time and technical systems is based on an originary human-technic relationship, or the constitution all temporal experience through the technical. Stiegler claims that this originary duality is the possibility of collective and technological evolution, through which the external technical milieu inscribes in the human the possibility to constitute its consciousness in the present and over time. Stiegler's philosophical analysis in Technics and Time (Vols. 1 and 2) sets out an agenda to think through a tension between human life and the technical. Briefly, Stiegler considers that the creation of all artifacts and technics is actually the exteriorization of human impulses into material form. (Words capture human speech, machines replicate human gestures, information technology substitutes for the human senses). This act is not simply the exteriorization of the subject into the world. It is also, at its most basic understanding, the act of "living" (forming consciousness) by means other than organic means. Humanity is always already technical, through both the co-constitution of humanity with technics as well as humanity's own self-constitution through exteriorization. For this reason, Stiegler confidently claims that interiority (of the subject) is nothing more than its exteriorization. By ascribing an originary technicity to human life, Stiegler wishes to move the political study of humanity beyond Rousseau's idea of “a pretechnical magical humanity: the magic unity is that which in effect, except for these key points, has not yet analytically separated forms from ground, that is, schema, which only later will become, as technical tools, movable objects." (Stiegler http:/ /www.arsindustrialis.org/anamnesisand-hypomnesis, February 20, 2010)

Therefore, Stiegler's innovative approach to the experience of time and memory is not based simply on human perception. Instead, he makes it clear that human experience (of any kind) is only possible through the "movement" of consciousness between humans and technics, and that human experience itself unfolds through a back and forth relationship with technical objects that house externalized human impulses and ideas accumulated over time. Stiegler cites the development of the technical into its current manifestation as an industry of real time as an important factor for social theory to consider. However, this development of breaking the 'time barrier' (by means of real time) can be nothing short of a total redefinition of the form of the relationship between humans and technology. For Stiegler, the power of real-time technologies and the instantaneity of retrievable data is constitutive of the possible form(s) the resulting human-technical relation can take. Therefore, according to Stiegler's analysis, speed is constitutive of the evolving form(s) of human life itself. The imposition of real time privileges the circulation of information between machines and redefines the co-constitutive relationship between people and the technical.

If life is always already technical from its origin, then the experience of lived time is impossible without constituting human consciousness through technics and living through means of this co-constitution. In Heidegger's analysis of time, technics and instrumental rationality have enabled a form of revealing such that the "authentic temporality" of being is only possible through a rupture with the everyday "enframing" power of technology. "For Stiegler, however, everyday equipment or ready-to-hand beings available for use should be understood, rather, as the enabling condition- rather than the ontic obstruction of our phenomenological experience of temporality, above all our authentic appropriation of finitude or comportment towards death." (Sinnerbrink 2009) While he simultaneously finds inspiration and contention in Heidegger's work, Stiegler has an equally ambivalent relationship with Husserl's phenomenology. Husserl's work On Phenomenology and the Consciousness of Internal Time, identifies and details the primary and secondary retentions as constituting human memory. While these concepts are valid in Stiegler's view, Husserl makes a mistake by not also including the notion of tertiary retention, or the memory of culture in the form of external objects and the material (technical) systems in which we operate. Technics are tertiary retention, acting as constitutive systems of human memory, externalized impulses or actions. "If time-consciousness can be shown to rely on a mediation by a technically constituted object- what Husserl calls the temporal object- then the very 
content of the self on Husserl's account, the consciousness of the self flowing in time, would itself be dependent on technical mediation." (Hansen 2004: 595) Through generations of interaction with external objects, human memory is inscribed in the technical, as we export our immediate primary retentions and remembered secondary retentions into words, pictures, recordings, art, digital data and other (im)material forms. This form of exteriorized memory "does not belong to the lived experience that is, for Husserl, the sole originary and constitutive realm.” (Stiegler 2009a: 6) Rather, Stiegler introduces a totally new constitutive realm of the human-technical, simultaneously indicative of the experience of acting immediately as well as acting through the externalized memory of our technical surroundings.

Human interaction with these technical forms generates two results. These are indicative of a dual structure of experience. On the one hand, all these technical projections (as a tertiary form of a cultural past) act to replace/ challenge primary retention (immediate memory) in the constitution of consciousness. The very form of their flow, and their reception by society, is determined by instrumental speed of the image sequence (how fast the images reach the human). On the other (Heideggerean) hand, the real time flow of virtual space creates a condition of experience where the formation of human consciousness is secondary to establishing a particular human orientation (or connectivity) toward information flows. The unfolding of experience through digital culture, social networking, mobile devices and big data is simultaneously the unconscious orientation of social behavior toward real time technology and big data. This social orientation toward interactivity is compatible with the technocratic management of social spaces, which justifies the expansion of big data initiatives and government and corporate information collection programs designed to capture "everything" about consumers.

\section{| Missing Data, New Algorithms and Pattern Recognition}

I believe Stiegler is correct when he insists that the main political challenge of the hyperindustrial era will be the power struggle over the politics of memory, and perhaps more specifically, struggle of consciousness in real time. In this struggle, many actors may turn to strategic means such as data deletion to either assert their autonomy relative to the ubiquity of the networked information economy, or to manage their information data double in such a way that it helps them cope with the inevitability of losing the struggle for memory. However, as I argued earlier, the act of user-initiated deletion is still an affirmative act that requires an exercise of conscious or subconscious impulse. This exercise is an internal impulse that will inevitably become exteriorized in some form of external memory. In this sense, these impulses for deletion would be externalized in the data archives which govern the information architecture of our daily lives. The internal impulses of privacy, autonomy, defiance, or paranoia would find immaterial expression in the archives as blindspots, missing data and blanks.

As Mayer-Schönberger points out, big data "combine(s) innumerous bits of information about us, each one (at best) having been valid at a certain point in our past. But as it is presented to us, it is information from which time has been eliminated; a collage in which change is visible only as tension between two contradicting acts, not as an evolutionary process, taking place over time.” (2009: 124) Archives as generative, algorithmically governed processes do not present contextless data, but rather generate data points through the combination and integration of existing data. Deleted data will be scrubbed from that algorithmic process and will alter the possible information that can be retrieved from the archive. However, I'd like to suggest that it is just a matter of time before the algorithms which govern these generative processes begin to take into account the exteriorized impulse to delete. The processes which mathematically tie data together to yield a specific search result can likely be rethought to tie data gaps together, based on recognizing patterns in user deletion habits, to yield a different, yet similarly dynamic and retrievable data image. There are two specific ways in which the conditions of archivization could evolve to make significant use of deleted data as a tool for organizing retained data. The first possibility is that data gaps will be filled in by a calculations meant to anticipate and approximate, based on available data sources, what would have been available had it not been deleted. The other possibility is that new algorithms may be developed to re-present a series of deleted data gaps to form a new piece of data based on pattern recognition.

First, consider Amelia II. Social scientist Gary King and colleagues recently tackled the "problem" of missing data by creating a software program, Amelia II, which runs a series of calculations to approximate the value of missing data points within data sets. They explain their program as such:

Missing data is a ubiquitous problem in social science data. Respondents do not answer every question, countries do not 
collect statistics every year, archives are incomplete, subjects drop out of panels. Most statistical analysis methods, however, assume the absence of missing data, and are only able to include observations for which every variable is measured. Amelia II performs multiple imputation, a general-purpose approach to data with missing values. This method creates multiple "filled in" or rectangularized versions of the incomplete data set so that analyses which require complete observations can appropriately use all the information present in a data set with missingness. Multiple imputation has been shown to reduce bias and increase efficiency compared to listwise deletion. Furthermore, ad-hoc methods of imputation, such as mean imputation, can lead to serious biases in variances and covariances. Unfortunately, creating multiple imputations can be a burdensome process due to the technical nature of algorithms involved. Amelia II provides users with a simple way to create and implement an imputation model, generate imputed datasets, and check its using diagnostics. (Honaker, King and Blackwell 2011:1-2)

This statistical software demonstrates that with the right statistical savvy, new data can be generated so as to effectively replace data. Of course, the problem here is that Amelia II's imputation method must assume "as most multiple imputation methods do, that the data are missing at random (MAR). This assumption means that the pattern of missingness only depends on the observed data Dobs, not the unobserved data Dmis." (Honaker, et al 2011: 3) This is precisely the exact type of assumption one cannot make when we consider data deletion as a method for navigating the power structures of information economies. The act of deletion tends to be deliberate, focusing on privacy or autonomous choice. It will certainly be employed toward specific sensitive or personal data and in an entirely non-random fashion. Thus, while the multiple imputation method is seemingly lacking in approximating nonrandomly deleted information, the statistical wheels are in motion to develop big data analytical tools to overcome the obstacles that deliberate deletion may pose down the road.

Secondly, I'd also like to suggest that algorithms may be developed to piece together and generate new data based on the unintentional data points created when one chooses to delete information. Unlike the software package outlined above, this approach would not seek to complete a dataset with approximated values. Instead, such a proposed program would seek to generate a drastically unique representation of individuals based on the negation of their data profiles. They would sketch the space between data points to create a new data image. By recognizing patterns about when, how often, with what frequency, in what context and in conjunction with which other activities deletion takes place, algorithms may come into play that do not aim to fill in missing data gaps, but aim to generate an entirely different and drastically different data profile of individuals. This profile would be based not on what has been collected, but rather based on what one tries to hide.

According to Mayer-Schönberger, he believes that a major problem to easy retrieval which employs abstract categorizations is that (relatively speaking) it provides less contextual information/background than earlier methods of analog retrieval. (2009: 78) Yet, he also points out that software engineers are actively trying to overcome decontextualized retrieval by recontextualizing data for the searcher once the search is underway. (Mayer-Schönberger 2009: 79) It is all too predictable that the "recontextualizing" of data will include inputs from data generated through the analysis of deleted, obsolete or redundant information. If the impulse to hide data does get inscribed into the conditions of archivization and retrieval methods, it will be a direct reflection of the social desire for privacy or the sense of suspicion toward data surveillance. Ironically, the urge to delete will undoubtedly lead to new methods of analysis that seek to recontextualize through increasingly decontextualized data sources. Therefore, the process of data retrieval will become even more algorithmic and statistical and move even further away from Mayer-Schönberger's goal to "rehumanize" the social relationship with the permanence of digital data storage.

\section{Conclusion: Inscribing Anxiety into the Digital}

Between the recent announcements and revelations that U.S. government surveillance on its citizens was far greater than suspected, and the recent spike in both STS and humanities scholars exploring big data through humanistic and theoretical approaches, public consciousness about personal data security, data tracking and surveillance has definitely elevated. In turn, the simple observation that there is a heightened sense of concern about the relationship between individuals and "their" data prompted me to undertake this project. Undoubtedly, feelings are changing regarding ownership of data, collection and retention of information and how governments or corporations should be allowed to use such data. However, precisely because so many ethical questions and raw emotions have been stirred up by the recent debates on big data, we must stop to ask one last major question. Rather than focusing on the ownership of data (a legal question) or the ethics of big data and surveillance (ethical and political questions) 
I believe it is important to ask a philosophical question about the technological conditions that make archivization possible.

Stiegler has demonstrated that our temporal consciousness can only come into existence through the interplay of primary, secondary and tertiary memory. Tertiary memory is externalized cultural memory in the form of technics, procedures, language, hardware, software and data, and the relative speed and intensity of our relationship with our external surroundings has allowed tertiary memory to over determine (relative to primary and secondary retentions) our consciousness in the present.

\begin{abstract}
Stiegler's theory of technics as tertiary memory is simultaneously a theory of the archive, technics as an ever-growing storehouse, the material/ideal manifestation and repository of human knowledge and experience. Moreover, under real-time computing and information dissemination, and the concomitant development of an unimaginable array of technologies for data and media storage in public and private, domestic and commercial settings, we find ourselves surrounded by technologies of the archive as much as technics as the archive. But archives are about more than simply the storage of information, of records of the past, of events. (Cooke: 2009)
\end{abstract}

If digital memory as tertiary memory is over determining the present human-technical relationship, we must ask: what memory and impulse will be inscribed into the digital and algorithmic fabric of tertiary memory if we choose to delete information? What impulses and emotions will become part of our cultural memory if we are inscribing blind spots into data which co-constitutes our existence? I argue that the primary feelings and emotions associated with data deletion are less about caution, prudence or Nietzschean will to power and more closely related to anxiety, suspicion, and fear of diminishing autonomy. I also argue that even the attempt to delete information (to hide that which represents our exteriorized interiors) is itself an externalized impulse that ultimately is inscribed into the technical environment through the process of individuation which occurs between humans and digital tools. Deletion does not simply remove memory from data stores. Because it involves a social process, multiple parties, varying costs and the creation of additional metadata, deletion is very much an active inscription into memory. This inscription permanently ties anxiety and suspicion into technical architecture in both the inscription of deleted data gaps, but also the metadata threads that emerge from the deletion process. This architecture, simultaneously composed of data and blindspots, operates in a constitutive manner in such a way that it will constantly reinscribe these impulses into populations as the process of technical individuation impacts the emergence of human consciousness in the era of big data.

As I have suggested, the urge to delete will lead to market-driven technological programs designed to overcome deletion through re-contextualizing, or approximating data. Or, new technological solutions will benefit from the urge to delete by creating programs that they can sell to consumers to assist them with the deletion process. The technical supplements that force consciousness to emerge in ways compatible with the speed of contemporary society will certainly absorb the anxiety and suspicion associated with data deletion in ways that will be revisited upon individuals. I am well aware that the transductive processes that Stiegler identifies seemingly point towards technological determinism capable of absorbing virtually any shock to the system. Many critics have pointed this out. However, let us also remember that Stiegler refuses to be a philosopher for the pessimists. His later work on education and long-circuit attention offers some potential progress to be made in the battle "for a politics of memory, and more precisely, for the constitution of sustainable hypomnesic milieux." (Stiegler http://www.arsindustrialis. org/anamnesisand-hypomnesis, February 20, 2010) Likewise, though Mayer-Schönberger does not seem to share Steigler's belief in the originary technicity of humans, he also proffers some potential aids in the fight for privacy and prudence through legal means, market mechanisms and cooperative social relationships. Though the battle for a politics of memory is complicated, the conscious choice to delete is not the answer. It is but a new factor that will certainly be incorporated into the architecture and algorithms of archives, and a factor that deserves more attention from social scientists, legal scholars, philosophers and information technology scholars. 


\section{References}

Cooke, Grayson 2009. "The Cosmeceutical Face: Time Fighting Technologies and the Archive." Transformations. 17. http:// www.transformationsjournal.org/journal/issue_17/article_03. shtml. Accessed April 15, 2010.

Ernst, Wolfgang 2012. Digital Memory and the Archive. Minneapolis: University of Minnesota Press.

Hansen, Mark 2004. "The Time of Affect, or Bearing Witness to Life." Critical Inquiry Vol.30, No. 3: 584-626.

Honaker, James, Gary King and Matthew Blackwell 2011. "Amelia II: A Program for

Missing Data." Journal of Statistical Software, 45(7): 1-47.

Kafka, Ben 2012. The Demon of Writing: Powers and Failures of Paperwork. Zone Books.

Mayer-Schönberger, Viktor 2009. Delete: The Virtue of Forgetting in the Digital Age. Princeton, NJ: Princeton University Press.

Mills, Mark P. 2013. "Every Breath you Take." Book review of Big Data: A Revolution That Will Transform How We Live, Work, and Think, by Viktor Mayer-Schönberger and Kenneth Cukier, City Journal Vol. 23, No. 3. http://www.city-journal.org/2013/ bc0702mm.html. Accessed April 11, 2014.

Parikka, Jussi 2011. "Operative Media Archeology: Wolfgang Ernst's Materialist Media Diagrammatics." Theory, Culture \& Society. Vol. 28, No. 52: 52-74.
Pinch, Trevor J. and Wiebe E. Bijker 2003. "The Social Construction of Facts and Artifacts." Pp. 221-232 in Philosophy of Technology- The Technological Condition: An Anthology, edited by Robert C. Scharff and Val Dusek. Malden, MA: Blackwell Publishing.

Stiegler, Bernard 1998. Technics and Time, Vol. 1, The Fault of Epimetheus. Stanford, California: Stanford University Press.

Stiegler, Bernard 2009a. Technics and Time, Vol. 2, Disorientation. Stanford, California: Stanford University Press.

Stiegler, Bernard 2009b. "The Theater of Individuation: PhaseShift and Resolution in Simondon and Heidegger." Parrhesia. No. 7: 46-57.

Stiegler, Bernard and Irit Rogoff (2010) "Transindividuation." e-flux journal, No. 14. http://www.e-flux.com/journal/ view/121. Accessed April 15, 2010.

Stiegler, Bernard "Desire and Knowledge: the Dead Seize the Living." http://www.arsindustrialis.org/desire-and-knowledge-dead-seize-living. Accessed January 3, 2010.

Stiegler, Bernard "Nanomutations, Hypomnemata and Grammatisation.” http://www.arsindustrialis.org/node/2937 . Accessed January 3, 2010.

Stiegler, Bernard "Anamnesis and Hypomnesis." http://www. arsindustrialis.org/anamnesis-and-hypomnesis. Accessed February 20, 2010 
